\title{
Characterization of Vertical Accelerations Experienced by Older People Attending an Aerobics Class Designed to Produce High Impacts
}

\author{
Kimberly Hannam, Kevin Deere, Sue Worrall, April Hartley, and Jon H. Tobias
}

\begin{abstract}
The purpose of this study was to establish the feasibility of using an aerobics class to produce potentially bone protective vertical impacts of $\geq 4 g$ in older adults and to determine whether impacts can be predicted by physical function. Participants recruited from older adult exercise classes completed an SF-12 questionnaire, short physical performance battery, and an aerobics class with seven different components, performed at low and high intensity. Maximum $g$ and jerk values were identified for each activity. Forty-one participants (mean 69 years) were included. Mean maximal values approached or exceeded the $4 g$ threshold for four of the seven exercises. In multivariate analyses, age $(-0.53$; $-0.77,-0.28)$ (standardized beta coefficient; $95 \%$ CI) and 4-m walk time $(-0.39 ;-0.63,-0.16)$ were inversely related to maximum g. Aerobics classes can be used to produce relatively high vertical accelerations in older individuals, although the outcome is strongly dependent on age and physical function.
\end{abstract}

Keywords: accelerometry, exercise, older adults

Hip fracture is a major cause of morbidity and mortality in older people, leading to loss of independence and a huge economic burden through both direct medical costs and social sequelae (Burge, 2001). It is thought that age-related declines in the intensity and quantity of physical activity (PA) contribute to this increase in risk of osteoporotic fracture. Promotion of PA in older people is thought to help maintain bone mass; epidemiological studies report that risk of hip fracture is reduced in older adults who remain more physically active (Moayyeri, 2008). An important physiological link exists between exercise and bone, as demonstrated by findings from animal studies over 30 years ago. These studies found that the skeleton is exquisitely responsive to mechanical strain; bone loss caused by immobilization was prevented by only four loading cycles per day (Rubin \& Lanyon, 1984). There is little evidence that walking interventions improve bone mineral density (BMD), as judged by findings of a 2008 meta-analysis (Martyn-St James \& Carroll, 2008). In contrast, protocols that combined jogging, walking, and stair climbing consistently improved hip BMD in older people (Martyn-St James \& Carroll, 2009). Interventions to increase aerobic activities, high-impact exercises, "odd-impact" exercise loading, and resistance training (designed to increase bone loading through increased muscle strength) also improve hip BMD in this group (Allison, Folland, Rennie, Summers, \& Brooke-Wavell, 2013; Marques et al., 2011; Martyn-St James \& Carroll, 2009, 2010; Nikander et al., 2009).

Therefore, exercise interventions in older people may need to achieve relatively high levels of impact to be effective at increasing BMD. High-impact PA produces deformation of lower limb bones, including sites such as the hip, as a consequence of ground reaction forces, which occur on landing. Bone strain resulting from a given movement reflects not only ground reaction forces, but also local actions of muscle which serve to amplify externally applied forces due to the short levers they work with (Ireland, Rittweger, \&

Hannam, Deere, Hartley, and Tobias are with the Musculoskeletal Research Unit, University of Bristol, Bristol, UK. Worrall is with the University of Bristol Centre for Sport, Exercise and Health, Bristol, UK. Address author correspondence to Kimberly Hannam at kimberly.hannam@bristol.ac.uk.
Degens, 2014). Hence, muscle performance also needs to be taken into account when assessing relationships between high-impact PA and the skeleton. As well as providing objective measurement of vertical impacts through measurement of vertical axis accelerations, accelerometers attached to the center of mass can also be employed to evaluate other aspects of muscle performance, as in a recent study of training effects on maximum jerk during a sit-to-stand activity (Regterschot et al., 2014). Jerk is a measure of the rate of change in acceleration, and reflects the rate of force development (also termed rate of joint torque development).

In our previous study based on adolescents from the Avon Longitudinal Study of Parents and Children wearing accelerometers at home for up to seven days, we found that the relationship between habitual levels of PA and hip BMD could be explained by the number of albeit rare vertical accelerations above $4.2 \mathrm{~g}$ (beyond earth's gravitational force), which are typically achieved by jogging at speeds of $10 \mathrm{~km} / \mathrm{hr}$ or more (Deere, Sayers, Rittweger, \& Tobias, 2012). Similarly, the number of vertical accelerations beyond $3.9 g$ in postmenopausal women, achieved during activities such as jumping in supervised exercise classes, was related to gain in hip BMD (Vainionpaa et al., 2007; Vainionpaa et al., 2006). However, there has been little attempt to quantify target levels of impact for preserving bone in older individuals, or the extent to which these are generated by PA interventions in this age group. Therefore, we examined this question in a recent pilot study based on 20 older participants (mean age 67 years) who were asked to wear accelerometers while attending a typical aerobics exercise class. Interestingly, no vertical accelerations were recorded beyond $2.1 g$ (Tobias et al., 2014), suggesting that, in older people, it may not be feasible to achieve the level of impacts found to be bone protective in younger individuals.

In this study, we investigated whether higher $g$ levels, similar to those found to be bone protective in younger individuals, can be achieved in older individuals by modifying the content of aerobics classes. We also examined whether the level of impacts achieved in this setting can be predicted by physical and mental function as reflected by the physical and mental components of the SF-12 questionnaire, and the short physical performance battery (SPPB) (Guralnik et al., 1994). In addition, we investigated whether physical and mental function, as measured by these instruments, are also 
related to accelerometry-based assessment of muscle function, as reflected by jerk derived from vertical axis accelerations.

\section{Methods}

\section{Study Design}

We recruited male and female participants from a mixed exercise class aimed at older adults, based at the University of Bristol Sports and Exercise Centre. Class members were provided with an explanation of the study along with an invitation pack, which included a participant information leaflet, reply slip, consent form, the SF-12 health survey, and a freepost envelope. No exclusion criteria were used. On attendance at one of three standardized exercise sessions carried out on consecutive weeks, participants were fitted with an accelerometer immediately before the start of the exercise class, and completed an SPPB test immediately after. The study protocol was approved by the Faculty of Medicine and Dentistry Research Ethics Committee at the University of Bristol. All study participants provided informed written consent before participating in the study.

\section{Exercise Class}

The class was designed in collaboration with the exercise instructor (SW) responsible for delivering the sessions, with the aim of including components which produce relatively high impacts that can be reproduced consistently and safely in older individuals. Each class lasted a total of $45 \mathrm{~min}$, which included a 15-min warm-up and 10-min cool-down. The exercise sequence is shown in Table 1. Each component comprised seven movement repetitions, which were initially performed at low intensity, and then repeated at higher intensity if participants felt able to do so. Consecutive components were interspersed with a holding move of gentle side-to-side steps for $30 \mathrm{~s}$ to aid identification of separate components within the data. External factors were optimized to encourage higher impacts including the tempo and genre of the music played, the dimensions, heating and lighting in the exercise room, the delivery style of the instructions provided throughout the class, and the explanation that our study was about the health benefits of high-impact exercise.

\section{Accelerometers}

At the start of each exercise class, participants were fitted with a triaxial accelerometer (Gulf Coast Data Concepts Series $\times 16-1 C$, Waveland, MS). These are small, portable, sealed self-contained units that record movement in three axes of movement at a frequency of $50 \mathrm{~Hz}$. The monitors were fitted to participants by the research team in a secure size-specific elasticated belt, horizontally on their right hip so that vertical axis accelerations of the center of mass could be identified. The custom-designed belts ensured the accelerometers maintained a consistent position throughout the exercise class. Real-time clock software installed on each accelerometer enabled the timing of each movement to be recorded. Individual comma-separated values (CSV) data were converted to a Stata (v. 13; StataCorp, College Station, TX) data file and variables were derived using custom code. Vertical axis accelerations were examined for separate exercise components for each participant, and the single highest (peak) $g$ was identified. Jerk was obtained by dividing the difference between each acceleration and the acceleration recorded immediately beforehand, by time elapsed. As jerk was used as an estimate of muscle performance working against gravity, these analyses were based on negative vertical axis values. For the purposes of this study, the accelerometry-derived variables included peak $g$ (based on the highest value experienced by participants during the exercise class as a whole), peak jerk (maximum jerk based on the mean of the top 10 jerks experienced during the class), aggregate $g$, and aggregate jerk (maximum values averaged across all seven high-intensity components).

\section{Questionnaire}

An SF-12 questionnaire was provided to all participants before the aerobics sessions. The short-form questionnaire comprises 12 questions to ascertain self-reported functional health and wellbeing. Eight health domains are covered: physical functioning, role physical, bodily pain, general health, vitality, social functioning, role emotional, and mental health (Busija et al., 2011). A mental component score (MCS) and physical component score (PCS) are aggregate summary measures which can be derived from summing factor-weighted scores across the eight health domains based on a

\section{Table 1 Exercise Components of the Aerobics Class Session}

\begin{tabular}{|c|c|c|c|c|}
\hline Order & Type of Movement & Movement Description & Low Intensity & High Intensity \\
\hline 1 & Step-ups on and off bench & Step R up, L up, R down, L down. & No jumping & Jump down \\
\hline 2 & Jacks & $\begin{array}{l}\text { Start with feet together, hands by side. Tap R leg out and lift both } \\
\text { arms out to the side. Return to start position. Repeat other side. }\end{array}$ & Half jack & Jumping jack \\
\hline 3 & Alternate leg mambo & $\begin{array}{l}\text { Step forward on } \mathrm{R} \text {, step back on } \mathrm{L} \text {, bring feet together and raise } \\
\text { both heels and lower. Repeat on other side. }\end{array}$ & Heel raise on return & Jump on return \\
\hline 4 & Spotty dogs & $\begin{array}{l}\text { Feet together, tap alternate legs behind and back together. Arms } \\
\text { reach forward or overhead. }\end{array}$ & Back tap (no jump) & $\begin{array}{l}\text { Switch legs (with } \\
\text { spring) }\end{array}$ \\
\hline 5 & Double hamstring curl & $\begin{array}{l}\text { Feet apart. Step onto } \mathrm{R} \text { foot, bend } \mathrm{L} \text { knee, bringing heel to buttock } \\
\text { (knee pointing down to floor). Tap } \mathrm{R} \text { foot down and pick heel up } \\
\text { again. Step onto } \mathrm{L} \text { foot and repeat all on opposite side. }\end{array}$ & $\begin{array}{l}\text { No jumping/ } \\
\text { hopping }\end{array}$ & With jump and hop \\
\hline 6 & Knee lifts & Step onto R, picking up L knee toward chest. Repeat on other leg. & Low level & With jump and hop \\
\hline 7 & March/spring on spot & Brisk march on the spot, bringing up knees and swinging arms. & Marching & $\begin{array}{l}\text { Speed sprint on } \\
\text { spot }\end{array}$ \\
\hline
\end{tabular}

Note. Table shows the seven exercise components with the high- and low-intensity version of each included in the aerobics class. 
U.S.-based general population sample. The mean score from this sample can be used to dichotomize participants based on whether they fall above or below this point (Ware, Kosinski, \& Keller, 1996).

\section{Physical Functionality Test}

Participant physical functioning was objectively individually assessed with the widely-used SPPB test (Guralnik et al., 1994). The test consists of three balance tests in which the participant is instructed to stand as long as they are able to (for a maximum of $10 \mathrm{~s}$ ) in a side-by-side, semitandem, and tandem stand position. Participants are then timed to walk at their normal pace for $4 \mathrm{~m}$ (this was performed twice and their best time taken). The final element of the SPPB is a chair rise test. Participants perform an initial 'pretest' to ensure they are competent in standing up from a chair with both arms across their chest. Provided this can be performed, participants are timed to carry out five chair rises as fast as possible without the use of their arms. A maximum score of four can be achieved in each of the three test elements.

\section{Statistical Analysis}

The SPPB showed a strong ceiling effect, reflecting the self-selected nature of our study participants, and so separate components (i.e., gait speed and chair rise time) were also analyzed. Maximum $g$ (expressed as over and above $1 g$ caused by the earth's gravitational force) for each participant was identified across the exercise class as a whole. Aggregate maximum $g$, obtained from averaging maximum $g$ across all seven high-intensity components, was also derived. Maximum $g$ for each component of the exercise class was obtained by combining the maximal value observed for each participant. Maximum jerk was derived by averaging the top 10 jerk values obtained for each exercise component. Aggregate maximum jerk was obtained for each participant by averaging maximum jerk values across all seven high-intensity exercise components. Summary statistics from SF-12 questionnaires, the SPPB, and accelerometers were reported for males and females separately and combined, expressed as mean and $S D$. To examine relationships between general function and exercise class performance, regression analyses using standardized variables were performed using the SF-12 MCS, SF-12 PCS, gait speed, and chair rise time as exposures, and aggregate peak $g /$ jerk as outcomes, in males and females combined. Univariate analyses were performed initially, followed by multivariable analyses adjusted for age, sex, and other exposures.

\section{Results}

\section{Participant Characteristics}

A total of 41 participants ( 7 men and 34 women) were recruited. Table 2 presents the basic characteristics and health assessment scores. The mean age was 69 years (SD: 6 years). The group had a relatively high level of physical function, with $80 \%$ scoring $12 / 12$ on the SPPB test (mean: 11.7, SD: 0.8 ) and $78 \%$ of participants scoring above the average (based on U.S. population data) score for the physical component of the SF-12 questionnaire. MCS and PCS, SPPB score, gait speed, and chair rise time were similar in males and females.

The aggregate and maximum $g$ were similar between males and females, however, there was some evidence that aggregate jerk was higher in males (Table 3). Aggregate maximum $g$ scores across all seven high-intensity components were relatively high at $3.6 g$, with slightly higher values in males compared with females $(p=.73)$ (see Table 3). Maximum $g$, based on the highest $g$ value recorded across the whole exercise class, was higher still at $5.3 g$, again with higher values in males compared with females $(p=.33)$. Aggregate maximum jerk for high intensity components combined was approximately $40 \%$ higher in males compared with females $(p=.06)$.

\section{Accelerometry Readings in Different Exercise Components}

Mean maximum $g$ associated with individual components of the aerobics class are shown in males and females combined in Figure 1. Low-intensity exercise was associated with peak impacts ranging from $1.5 g$ for knee lifts to $2.8 g$ for mambo. High-intensity exercise produced peak $g$ values, which were approximately $80 \%$ greater on average than those seen in low-intensity exercise, ranging from $2.5 \mathrm{~g}$

Table 2 Physical Characteristics of Study Participants

\begin{tabular}{|c|c|c|c|c|c|c|}
\hline \multirow[b]{2}{*}{ Characteristics } & \multirow[b]{2}{*}{$\mathbf{n}$} & \multicolumn{2}{|c|}{ Men } & \multicolumn{2}{|c|}{ Women } & \multirow{2}{*}{$\begin{array}{c}\text { Total } \\
\text { Mean } \pm S D(\%)\end{array}$} \\
\hline & & Mean $\pm S D(\%)$ & Range & Mean $\pm S D(\%)$ & Range & \\
\hline $\mathrm{n}$ & & $7(17.1)$ & & $34(82.9)$ & & $41(100)$ \\
\hline Age (years) & 41 & $67.6 \pm 3.3$ & $63.4-73.1$ & $69.6 \pm 6.5$ & $54.6-83.1$ & $69.2 \pm 6.1$ \\
\hline Mental component score (MCS) & 41 & $46.9 \pm 10.3$ & $27.3-59.5$ & $54.8 \pm 5.8$ & $40.5-62.3$ & $53.4 \pm 7.3$ \\
\hline $\mathrm{n}$ above $\mathrm{MCS}$ average & 41 & $2(28.6)$ & & $26(76.5)$ & & $28(68.3)$ \\
\hline Physical component score (PCS) & 41 & $52.3 \pm 11.1$ & $32.2-63.8$ & $49.7 \pm 8.0$ & $30.9-57.9$ & $50.1 \pm 8.5$ \\
\hline $\mathrm{n}$ above $\mathrm{PCS}$ average $\mathrm{e}^{\mathrm{a}}$ & 41 & $6(85.7)$ & & $26(76.5)$ & & $32(78.1)$ \\
\hline SPPB score (max of 12) & 41 & $11.4 \pm 1.1$ & $9-12$ & $11.7 \pm 0.7$ & $9-12$ & $11.7 \pm 0.8$ \\
\hline Gait speed time over $4 \mathrm{~m}(\mathrm{~s})$ & 41 & $3.2 \pm 0.4$ & $2.4-3.8$ & $3.4 \pm 0.63$ & $2.0-4.9$ & $3.3 \pm 0.6$ \\
\hline Time to perform 5 chair rises (s) & 41 & $9.6 \pm 3.8$ & $4.8-17.2$ & $9.3 \pm 2.30$ & $5.4-16.9$ & $9.3 \pm 2.6$ \\
\hline
\end{tabular}

Abbreviation: SPPB = short performance physical battery.

Note. Table shows the physical characteristics for the 41 aerobics class participants.

a Based on normative values from U.S. population data (Ware et al., 1996). 
for knee lifts to $4.6 \mathrm{~g}$ for jacks. Mean maximum jerk likewise varied between activities, with high-intensity versions of a given activity associated with approximately $66 \%$ higher jerk values on average compared with the low-intensity version (Table 4). Although there was little overall difference between sexes, higher impact activities such as jacks appeared to be associated with higher maximum jerk, and to a lesser extent maximum $g$, in males as compared with females.

\section{Health Status and Accelerometer Readings}

We analyzed relationships between age, sex, and indicators of health status, and aggregate maximum $g$ and aggregate maximum jerk across all seven high-intensity components, in the 41 study participants. Univariate analyses revealed that greater age and slower walk time were associated with lower aggregate maximum $g$, whereas a positive association was observed for PCS (Table 5). The associations with age and walk time were particularly strong, such that a one $S D$ increase in age and walk time was associated with 0.61 and
$0.51 S D$ decreases in aggregate $g$, respectively. Associations with age and walk time persisted in multivariate analysis, although the beta coefficient for the association with walk time was attenuated by approximately $30 \%$, whereas the association with PCS was no longer present.

Inverse associations were observed between aggregate maximum jerk and not only age and walk time, but also chair rise time, whereas a positive association was observed with PCS (Table 6). There was also weak evidence that maximum jerk was lower in females $(p=.06)$. These associations all persisted in multivariate analysis, though beta coefficients for the relationships with age and walk time were attenuated by approximately $40 \%$.

The association between walk time and aggregate maximum $g$ persisted after adjusting for aggregate maximum jerk, although the beta coefficient was reduced by approximately half (from -0.43 to -0.23 in age- and sex-adjusted model). In contrast, the association between chair rise time and maximum jerk was only reduced by $12 \%$ (beta coefficient from -0.25 to -0.22 ) after adjusting for aggregate maximum $g$. The association between walk time and

Table 3 Physical Activity Recordings Summary in Males and Females

\begin{tabular}{|c|c|c|c|c|c|c|c|}
\hline & \multicolumn{2}{|c|}{ Female } & \multicolumn{2}{|c|}{ Male } & \multirow{2}{*}{$\begin{array}{c}\text { Female/Male Difference } \\
\boldsymbol{P}\end{array}$} & \multicolumn{2}{|c|}{ All } \\
\hline & Mean & $S D$ & Mean & $S D$ & & Mean & $S D$ \\
\hline Aggregate $g\left(\mathrm{~m} / \mathrm{s}^{2}\right)$ & 3.6 & 1.5 & 3.8 & 2.0 & .73 & 3.6 & 1.5 \\
\hline Maximum $g\left(\mathrm{~m} / \mathrm{s}^{2}\right)$ & 5.2 & 1.9 & 6.0 & 2.9 & .33 & 5.3 & 2.1 \\
\hline Aggregate jerk $\left(\mathrm{m} / \mathrm{s}^{3}\right)$ & 24.6 & 12.0 & 35.4 & 19.8 & .06 & 26. & 14.0 \\
\hline
\end{tabular}

Note. Table shows summary statistics for derived accelerometry variables based on all activities during the aerobics session in males $(n=7)$, females $(n=34)$, and entire cohort $(N=41)$. Maximum $g$ is based on the highest value experienced by participants during the exercise class as a whole, whereas aggregate $g$ and jerk represent maximum values averaged across all seven high-intensity components.

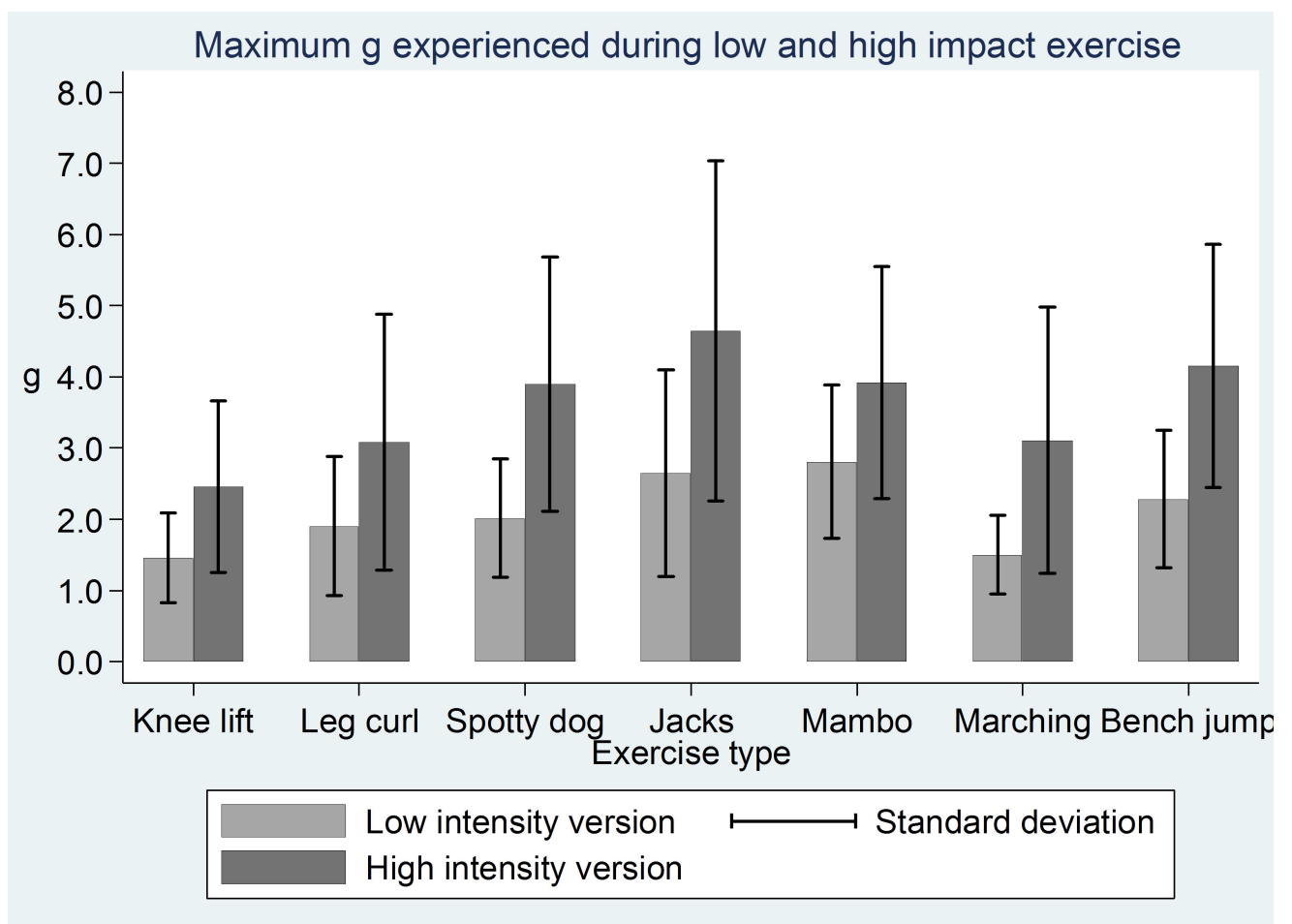

Figure 1 - Mean of the maximum $g$ experienced by participants during the low- and high-impact version of each of the seven aerobics movements $(N=41)$. 
Table 4 Mean of Maximum Jerk Experienced During Each Aerobic Activity

\begin{tabular}{|c|c|c|c|c|c|c|c|c|c|c|c|c|c|}
\hline \multirow[b]{2}{*}{ Activity } & \multirow[b]{2}{*}{ Intensity } & \multicolumn{4}{|c|}{ Female } & \multicolumn{4}{|c|}{ Male } & \multicolumn{4}{|c|}{ All } \\
\hline & & Mean & $S D$ & p25 & p75 & Mean & $S D$ & p25 & p75 & Mean & $S D$ & p25 & p75 \\
\hline \multirow[t]{2}{*}{ Knee lifts } & Low & 22.3 & 7.8 & 16.4 & 27.2 & 19.9 & 6.4 & 15.5 & 22.3 & 21.9 & 7.6 & 16.4 & 27.1 \\
\hline & High & 29.6 & 10.4 & 21.6 & 35.3 & 30.2 & 11.5 & 15.7 & 40.6 & 29.7 & 10.5 & 21.6 & 35.6 \\
\hline Hamstring curls & Low & 18.8 & 8.6 & 12.4 & 24.5 & 19.6 & 8.0 & 13.4 & 23.1 & 19.0 & 8.4 & 12.4 & 23.1 \\
\hline Spotty dogs & High & 33.5 & 14.2 & 22.8 & 43.3 & 35.9 & 17.9 & 18.1 & 47.4 & 33.9 & 14.7 & 22.8 & 43.3 \\
\hline \multirow[t]{2}{*}{ Jacks } & Low & 26.3 & 14.5 & 15.8 & 30.4 & 38.4 & 29.3 & 16.1 & 53.2 & 28.4 & 18.0 & 16.1 & 34.3 \\
\hline & High & 46.8 & 37.5 & 28.5 & 50.9 & 81.2 & 111.5 & 17.8 & 61.5 & 52.7 & 56.6 & 28.5 & 54.3 \\
\hline Marching & High & 81.9 & 52.2 & 46.9 & 99.8 & 87.4 & 74.7 & 28.4 & 96.8 & 82.9 & 55.6 & 46.9 & 98.0 \\
\hline \multirow[t]{2}{*}{ Bench steps } & Low & 33.0 & 10.0 & 24.7 & 39.0 & 32.9 & 21.4 & 18.2 & 35.7 & 33.0 & 12.3 & 24.0 & 39.0 \\
\hline & High & 43.3 & 20.2 & 28.1 & 51.6 & 60.6 & 38.4 & 36.2 & 75.6 & 46.2 & 24.5 & 30.6 & 55.7 \\
\hline
\end{tabular}

Abbreviations: $S D=$ standard deviation; $\mathrm{p} 25=25$ th percentile; $\mathrm{p} 75=75$ th percentile.

Note. Table shows summary statistics of the maximum jerk (based on the mean of the top 10 jerks experienced during the class) in the low-and high-intensity version of each aerobics class movement for the $n=7$ male and $n=34$ female participants.

Table 5 Associations Between Physical Activity Impact Predictor Variables with Aggregate Maximum $g$ from All Aerobics Movements

\begin{tabular}{|c|c|c|c|c|c|c|}
\hline \multirow[b]{3}{*}{ Variable } & \multicolumn{6}{|c|}{ Aggregate $g\left(\mathrm{~m} / \mathrm{s}^{2}\right)$} \\
\hline & \multicolumn{3}{|c|}{ Univariate Regression Analysis } & \multicolumn{3}{|c|}{ Multivariate Regression Analysis } \\
\hline & Coefficient & $95 \% \mathrm{Cl}$ & $p$ & Coefficient & $95 \% \mathrm{Cl}$ & $p$ \\
\hline Age (years) & -0.61 & $-0.87,-0.35$ & $<.001$ & -0.53 & $-0.77,-0.28$ & $<.001$ \\
\hline Sex (female) & 0.15 & $-0.70,1.00$ & .727 & 0.09 & $-0.57,0.74$ & .786 \\
\hline SPPB score (full marks) & 0.37 & $-0.43,1.17$ & .355 & 0.10 & $-0.52,0.72$ & .746 \\
\hline Walk time over $4 \mathrm{~m}(\mathrm{~s})$ & -0.51 & $-0.79,-0.23$ & .001 & -0.39 & $-0.63,-0.16$ & .002 \\
\hline Chair rise time $\times 5(\mathrm{~s})$ & -0.21 & $-0.52,0.11$ & .195 & -0.08 & $-0.33,0.18$ & .539 \\
\hline MCS & 0.07 & $-0.25,0.39$ & 667 & 0.24 & $-0.01,0.38$ & .061 \\
\hline PCS & 0.33 & $0.03,0.64$ & .033 & 0.13 & $-0.11,0.38$ & .270 \\
\hline
\end{tabular}

Abbreviations: $\mathrm{SPPB}=$ short performance physical battery; $\mathrm{MCS}=$ mental component score; $\mathrm{PCS}=$ physical component score .

Note. Table shows univariate and multivariate associations between aggregate maximum $g$ from all aerobics movements with age, sex, and indicators of health status $(n=41)$.

aggregate maximum jerk was no longer observed after adjusting for aggregate maximum $g$ (beta coefficient from -0.38 to -0.10 ).

\section{Discussion}

We evaluated the level of impacts achieved by older people participating in an aerobics class designed to produce relatively high impacts that are likely to be bone protective by using accelerometers worn over the hip to measure vertical accelerations. We found that participants generally achieved vertical accelerations in the region of $4 g$, a level previously suggested to have positive effects on BMD in adolescents (Deere et al., 2012) and premenopausal women (Vainionpaa et al., 2006). This contrasts with results of our previous study based on an equivalent study population, in whom virtually no accelerations were observed exceeding $2 g$ (Tobias et al., 2014). The success of the present aerobics class in achieving higher impacts is likely to reflect a combination of the types of exercise used and the intensity with which they were undertaken. For example, vertical accelerations in the region of $4 g$ were only achieved during exercises which involve rapid upward displacement of the center of mass (i.e., spotty dogs, mambo, jacks, and bench steps). Furthermore, accelerations of this magnitude were 


\section{Table 6 Associations Between Physical Activity Impact Predictor Variables with Aggregate Maximum Jerk from All Aerobics Movements}

\begin{tabular}{|c|c|c|c|c|c|c|}
\hline \multirow[b]{3}{*}{ Variable } & \multicolumn{6}{|c|}{ Aggregate Jerk (m/s³) } \\
\hline & \multicolumn{3}{|c|}{ Univariate Regression Analysis } & \multicolumn{3}{|c|}{ Multivariate Regression Analysis } \\
\hline & Coefficient & $95 \% \mathrm{Cl}$ & $p$ & Coefficient & $95 \% \mathrm{Cl}$ & $p$ \\
\hline Age (years) & -0.48 & $-0.76,-0.19$ & .002 & -0.28 & $-0.54,-0.02$ & .036 \\
\hline Sex (female) & 0.77 & $-0.04,1.58$ & .063 & 0.66 & $-0.04,1.35$ & .062 \\
\hline SPPB score (full marks) & 0.16 & $-0.65,0.96$ & .698 & -0.16 & $-0.82,0.50$ & .620 \\
\hline Walk time over $4 \mathrm{~m}(\mathrm{~s})$ & -0.47 & $-0.76,-0.18$ & .002 & -0.32 & $-0.57,-0.07$ & .014 \\
\hline Chair rise time $\times 5(\mathrm{~s})$ & -0.34 & $-0.64,-0.03$ & .030 & -0.32 & $-0.59,-0.05$ & .021 \\
\hline MCS & -0.13 & $-0.45,0.19$ & .418 & 0.13 & $-0.13,0.40$ & .315 \\
\hline PCS & 0.42 & $0.13,0.72$ & .006 & 0.26 & $0.01,0.52$ & .046 \\
\hline
\end{tabular}

Abbreviations: SPPB = short performance physical battery; MCS = mental component score; PCS = physical component score.

Note. Table shows univariate and multivariate associations between aggregate maximum jerk from all aerobics movements with age, sex, and indicators of health status $(N=41)$.

only observed when participants were explicitly encouraged by the instructor to exercise at high intensity.

Future studies will be required to determine whether an aerobics class structured along these lines is successful in improving BMD, based on trials where this forms the basis of a PA intervention. That such a strategy is likely to be effective is supported by previous observations that interventions expected to produce high impacts, such as hopping, appear to be effective at increasing hip BMD in older individuals (Allison et al., 2013). However, the level of impacts produced was not generally recorded in previous interventional studies in this age group, and it is unclear how comparable these were to the present aerobics class in terms of delivery of osteogenic PA. In contrast, previous well-conducted exercise intervention studies in older adults have found some evidence of benefit in preventing fall-related fractures, yet no positive effect on BMD (Korpelainen, Keinanen-Kiukaanniemi, Heikkinen, Vaananen, \& Korpelainen, 2006; Uusi-Rasi et al., 2015). Whereas these negative studies could be a reflection of the types of exercise used, our results suggest that participant characteristics might also play a role. Not surprisingly, we found that preexisting factors such as age and level of physical function strongly influences the level of impacts that an individual is able to achieve. Further studies are required to establish whether high-impact exercise interventions such as hopping and jumping also prove effective in increasing BMD in older, frailer populations.

Participants attending the aerobics class were a self-selected group, and had relatively high levels of function as reflected by baseline SF-12 and SPPB scores. That level of function as reflected by these scores was a strong predictor of performance in these classes was confirmed by our finding that age and walking time were both strong negative predictors of the level of vertical accelerations achieved. Hence, the SPPB, which is widely used clinically to screen for function and frailty in older people, may also prove useful in screening older individuals in terms of how likely they are to benefit from aerobics classes as a means of generating osteogenic PA.

Presumably, the relationship between gait speed and maximum $g$ during the aerobics class reflects the fact that accelerometer recordings while performing standardized activities at maximal intensity provide measurements of muscle performance. For example, in jumping mechanography, rate of acceleration while jumping is used to measure peak muscle force, which is in turn related to cortical bone geometry and strength (Hardcastle et al., 2014). Although jumping mechanography relies on the use of force plates rather than accelerometers to measure ground reaction forces, previous research has demonstrated a strong correlation between force plate measured peak ground reaction force and peak tibial axial accelerations during jumping (Elvin, Elvin, \& Arnoczky, 2007). More recently, a study in children wearing accelerometers at the hip observed good agreement between these two methods (Meyer et al., 2015).

Accelerometers can also be used to derive jerk, which reflects the rate of force development, and may represent a distinct aspect of muscle function as compared with maximum muscle force or power. A decrease in rate of force development has been reported to be an important contributor to declining muscle function in older men (Thompson, Ryan, Sobolewski, Conchola, \& Cramer, 2013) and a risk factor for falls in older women (Crozara et al., 2013). Although few previous studies have examined accelerometerderived measures of jerk, in one recent study maximum jerk was found to show expected improvements in response to training during a sit-to-stand activity in older people (Regterschot et al., 2014). Since rate of force development appears to be related to the ability to execute movements such as sit to stand, we reasoned that maximum jerk as measured during the aerobics class may be related to chair rise time. Interestingly, chair rise time was found to predict maximum jerk but not maximum $g$, providing face validity for the use of accelerometry-based measures of maximum jerk as a measure of rate of force development. More objective validation, based on participants wearing accelerometers during jumping mechanography, is planned as part of future studies.

In terms of limitations in this exploratory study to examine whether higher impacts are achievable in the setting of an aerobics class directed toward older individuals, several strategies were used concurrently, including alterations in the tempo of music played during the class, and in instructions given. Before wider implementation, it would be helpful to evaluate the relative importance of each strategy. Another limitation is that this study was based on a self-selected group; based on the relationship we observed between baseline functional status and maximum level of vertical accelerations achieved, subsequent application of this approach may need to be restricted to older people with similarly high levels of physical function. The accelerometers were fitted securely with custom-designed elasticated belts around each participant's waist by the research team to ensure that it was positioned correctly and were 
observed throughout the class; however, during the class, movement of the monitor may have resulted in some vertical impacts being partly distributed through the remaining two axis recorded by the triaxial accelerometer and thus could have resulted in an underestimation of $g$ forces experienced by participants. In conclusion, aerobics classes can be readily modified to ensure that participating older individuals experience levels of impacts that are likely to be bone protective. However, the success of this strategy in producing high impacts is strongly dependent on preexisting physical function as reflected by factors such as age and gait speed. Further research is justified to examine whether aerobics classes designed to produce high impacts are effective at improving BMD and strengthening weight bearing bones, and hence have a role as an adjunct to, or possible replacement of, conventional pharmacotherapy.

\section{Acknowledgments}

We are very grateful to all the study participants. This study was funded by the Medical Research Council, grant ref MR/K024973/1.

\section{References}

Allison, S.J., Folland, J.P., Rennie, W.J., Summers, G.D., \& Brooke-Wavell, K. (2013). High impact exercise increased femoral neck bone mineral density in older men: a randomised unilateral intervention. Bone, 53(2), 321-328. PubMed doi:10.1016/j.bone.2012.12.045

Burge, R.T. (2001). The cost of osteoporotic fractures in the UK: projections for 2000-2020. Journal of Medical Economics, 4, 51-62. doi:10.3111/200104051062

Busija, L., Pausenberger, E., Haines, T.P., Haymes, S., Buchbinder, R., \& Osborne, R.H. (2011). Adult measures of general health and healthrelated quality of life. Arthritis Care and Research, 63, S383-S412. PubMed doi:10.1002/acr.20541

Crozara, L.F., Morcelli, M.H., Marques, N.R., Hallal, C.Z., Spinoso, D.H., de Almeida Neto, A.F., . . G Goncalves, M. (2013). Motor readiness and joint torque production in lower limbs of older women fallers and non-fallers. Journal of Electromyography and Kinesiology, 23(5), 1131-1138. PubMed doi:10.1016/j.jelekin.2013.04.016

Deere, K., Sayers, A., Rittweger, J., \& Tobias, J. (2012). Habitual levels of high, but not moderate or low, impact activity are positively related to hip BMD and geometry: Results from a population-based study of adolescents. Journal of Bone and Mineral Research, 27(9), 1887-1895. PubMed doi:10.1002/jbmr.1631

Elvin, N.G., Elvin, A.A., \& Arnoczky, S.P. (2007). Correlation between ground reaction force and tibial acceleration in vertical jumping. Journal of Applied Biomechanics, 23(3), 180-189. PubMed

Guralnik, J.M., Simonsick, E.M., Ferrucci, L., Glynn, R.J., Berkman, L.F., Blazer, D.G., . . . Wallace, R.B. (1994). A short physical performance battery assessing lower extremity function: association with self-reported disability and prediction of mortality and nursing home admission. Journal of Gerontology, 49(2), M85-M94. PubMed doi:10.1093/geronj/49.2.M85

Hardcastle, S.A., Gregson, C.L., Rittweger, J., Crabtree, N., Ward, K., \& Tobias, J.H. (2014). Jump power and force have distinct associations with cortical bone parameters: findings from a population enriched by individuals with high bone mass. The Journal of Clinical Endocrinology and Metabolism, 99(1), 266-275. PubMed

Ireland, A., Rittweger, J., \& Degens, H. (2014). The influence of muscular action on bone strength via exercise. Clinical Reviews in Bone and Mineral Metabolism, 12, 93-102. doi:10.1007/s12018-013-9151-4

Korpelainen, R., Keinanen-Kiukaanniemi, S., Heikkinen, J., Vaananen, K., \& Korpelainen, J. (2006). Effect of impact exercise on bone mineral density in elderly women with low BMD: a population-based randomized controlled 30-month intervention. Osteoporosis International, 17(1), 109-118. PubMed doi:10.1007/s00198-005-1924-2

Marques, E.A., Wanderley, F., Machado, L., Sousa, F., Viana, J.L., MoreiraGoncalves, D., . . . Carvalho, J. (2011). Effects of resistance and aerobic exercise on physical function, bone mineral density, OPG and RANKL in older women. Experimental Gerontology, 46(7), 524-532. PubMed doi:10.1016/j.exger.2011.02.005

Martyn-St James, M., \& Carroll, S. (2008). Meta-analysis of walking for preservation of bone mineral density in postmenopausal women. Bone, 43(3), 521-531. PubMed doi:10.1016/j.bone.2008.05.012

Martyn-St James, M., \& Carroll, S. (2009). A meta-analysis of impact exercise on postmenopausal bone loss: the case for mixed loading exercise programmes. British Journal of Sports Medicine, 43(12), 898-908. PubMed doi:10.1136/bjsm.2008.052704

Martyn-St James, M., \& Carroll, S. (2010). Effects of different impact exercise modalities on bone mineral density in premenopausal women: a meta-analysis. Journal of Bone and Mineral Metabolism, 28(3), 251-267. PubMed doi:10.1007/s00774-009-0139-6

Meyer, U., Ernst, D., Schott, S., Riera, C., Hattendorf, J., Romkes, J., . . . Kriemler, S. (2015). Validation of two accelerometers to determine mechanical loading of physical activities in children. Journal of Sports Sciences, 33, 1702-1709. PubMed

Moayyeri, A. (2008). The association between physical activity and osteoporotic fractures: a review of the evidence and implications for future research. Annals of Epidemiology, 18(11), 827-835.

Nikander, R., Kannus, P., Dastidar, P., Hannula, M., Harrison, L., Cervinka, T., ... Sievanen, H. (2009). Targeted exercises against hip fragility. Osteoporosis International, 20(8), 1321-1328. PubMed doi:10.1007/ s00198-008-0785-x

Regterschot, G.R., Folkersma, M., Zhang, W., Baldus, H., Stevens, M., \& Zijlstra, W. (2014). Sensitivity of sensor-based sit-to-stand peak power to the effects of training leg strength, leg power and balance in older adults. Gait \& Posture, 39(1), 303-307. PubMed doi:10.1016/j. gaitpost.2013.07.122

Rubin, C.T., \& Lanyon, C.E. (1984). Regulation of bone formation by applied dynamic loads. The Journal of Bone and Joint Surg., 66, 397-402. PubMed

Thompson, B.J., Ryan, E.D., Sobolewski, E.J., Conchola, E.C., \& Cramer, J.T. (2013). Age related differences in maximal and rapid torque characteristics of the leg extensors and flexors in young, middle-aged and old men. Experimental Gerontology, 48(2), 277-282. PubMed doi:10.1016/j.exger.2012.10.009

Tobias, J.H., Gould, V., Brunton, L., Deere, K., Rittweger, J., Lipperts, M., \& Grimm, B. (2014). Physical activity and bone: may the force be with you. Frontiers in Endocrinology, 5, 20. PubMed doi:10.3389/ fendo.2014.00020

Uusi-Rasi, K., Patil, R., Karinkanta, S., Kannus, P., Tokola, K., LambergAllardt, C., \& Sievänen, H. (2015). Exercise and Vitamin D in Fall Prevention Among Older Women. A Randomized Clinical Trial. JAMA Internal Medicine, 175(5), 703-711. PubMed doi:10.1001/ jamainternmed.2015.0225

Vainionpaa, A., Korpelainen, R., Sievanen, H., Vihriala, E., Leppaluoto, J., \& Jamsa, T. (2007). Effect of impact exercise and its intensity on bone geometry at weight-bearing tibia and femur. Bone, 40(3), 604-611. PubMed doi:10.1016/j.bone.2006.10.005

Vainionpaa, A., Korpelainen, R., Vihriala, E., Rinta-Paavola, A., Leppaluoto, J., \& Jamsa, T. (2006). Intensity of exercise is associated with bone density change in premenopausal women. Osteoporosis International, 17(3), 455-463. PubMed doi:10.1007/s00198-005-0005-x

Ware, J, Kosinski, M., \& Keller, S.D. (1996). A 12-item short-form health survey - Construction of scales and preliminary tests of reliability and validity. Medical Care, 34(3), 220-233. PubMed doi:10.1097/00005650-199603000-00003 